\title{
Profiling the Expression of Genes Related to Ethylene Biosynthesis, Ethylene Perception, and Cell Wall Degradation during Fruit Abscission and Fruit Ripening in Apple
}

\author{
Jianguo Li \\ Virginia Polytechnic Institute and State University, Alson H. Smith, Jr. Agricultural Research and \\ Extension Center, 595 Laurel Grove Road, Winchester, VA 22602; and the College of Horticulture, \\ South China Agricultural University, Guangzhou 510642, China
}

\author{
Hong $\mathrm{Zhu}^{2}$ and Rongcai Yuan ${ }^{1}$ \\ Virginia Polytechnic Institute and State University, Alson H. Smith, Jr. Agricultural Research and \\ Extension Center, 595 Laurel Grove Road, Winchester, VA 22602
}

\begin{abstract}
Additional Index words. fruit abscission zone, fruit cortex, ethylene receptor, $\beta$-1,4-glucanase, Malus $\times$ domestica, polygalacturonase

Abstract. The expression of genes for ethylene biosynthesis, ethylene perception, and cell wall degradation in the fruit cortex and fruit abscission zone (FAZ) was examined in relation to preharvest fruit abscission (PFA) and fruit ripening in 'Golden Delicious' and 'Fuji' apple (Malus $\times$ domestica Borkh.). PFA, fruit ethylene production, and fruit softening increased rapidly during fruit ripening in 'Golden Delicious' apples, whereas no PFA, little fruit ethylene, and gradual fruit softening were recorded in 'Fuji' apples. The transcript levels of 1-aminocyclopropane-1carboxylate (ACC) synthase genes, $M d A C S 1, M d A C S 3$, and $M d A C S 5 A$, increased rapidly in the fruit cortex of 'Golden Delicious' apples during ripening, but not in 'Fuji' apples. However, only the level of MdACS5A mRNA was up-regulated in the FAZ of 'Golden Delicious' apples. The transcript level of ACC oxidase gene, MdACO1, increased in the fruit cortex for both cultivars but increased only in the FAZ of 'Golden Delicious' apples. Expression of the ethylene receptor genes, MdETR1, MdETR2, MdERS1, and MdERS2, increased in the fruit cortex for both cultivars, but only MdETR2 and MdERS2 increased in the FAZ of 'Golden Delicious' apples. The transcript levels of MdPG2, a polygalacturonase gene $(P G)$, and $M d E G 1$, a $\beta$-1,4-glucanase gene, markedly increased only in the FAZ of 'Golden Delicious' apples, whereas only MdPG1 rapidly increased in the fruit cortex of 'Golden Delicious' apples. Our results suggested that MdACS5A, MdACO1, MdPG2, and MdEG1 in the FAZ might be related to the difference in PFA between these two cultivars, whereas MdACS1 and MdPG1 were associated with fruit softening.
\end{abstract}

\begin{abstract}
Abscission is a complex, developmentally regulated, and genetically programmed process whereby organs such as leaves, flowers, or fruit are shed from the parent plant body (Bleecker and Patterson, 1997; Osborne, 1989; Roberts et al., 2002; Taylor and Whitelaw, 2001). Abscission occurs at predetermined sites referred to as abscission zones in response to developmental cues such as those occurring during fruit ripening or stresses, including drought, temperature extremes, wounding, chemical exposure, and pathogen attack (Osborne, 1989; Roberts et al., 2002). The plant hormone ethylene plays a regulatory role in abscission and can accelerate the process even though ethylene does not initiate abscission (Bleecker and Patterson, 1997; Patterson and Bleecker, 2004). Concomitant with increased ethylene production is increased expression of genes and activity of enzymes associated with cell wall degradation such as $\beta$-1,4-glucanase (cellulase or EG) and polygalacturonase (PG) (Bonghi et al., 2000; Brown, 1997;
\end{abstract}

Received for publication 24 Apr. 2009. Accepted for publication 14 June 2010. We gratefully acknowledge the financial support of the Virginia Agricultural Council and Virginia Apple Research Program. We also gratefully acknowledge the assistance of David H. Carbaugh and Grace Engelman.

${ }^{1}$ This paper is dedicated to the memory of Dr. Rongcai Yuan. He was a devoted plant scientist, a revered colleague and a kind mentor. He will be greatly missed by those who were privileged to know him.

${ }^{2}$ Corresponding author. E-mail: redspider19800915@gmail.com.
Roberts et al., 2002; Tucker et al., 1988). As a result, the middle lamellae of abscission zone cells dissolve and, ultimately, the organ abscises. Other genes such as pathogenesis-related genes and those involved in secondary metabolism and signal transduction are also up-regulated during the abscission process (Roberts et al., 2002).

The ethylene biosynthesis pathway has been well established in higher plants (Yang and Hoffman, 1984). The biosynthesis of ethylene begins with the production of S-adenosyl methionine (SAM) from the amino acid methionine. The conversions of SAM to 1-aminocyclopropane-1-carboxylate (ACC) and ACC to ethylene are the rate-limiting steps in ethylene biosynthesis and are catalyzed by ACC synthase (ACS) and ACC oxidase (ACO), respectively (Alexander and Grierson, 2002; Wang et al., 2002). Genes encoding ACS and ACO are members of multigene families, and their expression is differentially regulated by various developmental, environmental, and hormonal signals (Kende, 1993; Wang et al., 2002). After synthesis, ethylene is perceived by a family of membranelocalized receptors that are similar to bacterial two-component histidine kinase receptors (Bleecker and Kende, 2000; Klee, 2004; Wang et al., 2002). In arabidopsis [Arabidopsis thaliana (L.) Heynh.], there are five known ethylene receptors, ETR1, ETR2, ERS1, ERS2, and EIN4 (Wang et al., 2002). When ethylene binds receptors, ethylene receptors seem to undergo 
a conformational change and interact with the Raf-like serine/ threonine kinase CTR1, a negative regulator of the signal transduction pathway, and then the signal passes through a partially elucidated cascade that ultimately influences a myriad of ethylene-associated plant growth and development processes (Bleecker and Kende, 2000; Klee, 2004; Wang et al., 2002).

There is a lack of direct links between fruit ripening and abscission, but ripening fruit are usually abscised as an important strategy to facilitate seed dispersal (Addicott, 1982). Many apple cultivars such as Red Delicious and Golden Delicious have a serious preharvest fruit abscission problem, which occurs before fruit develop optimum color, maturity, or size (Schupp and Greene, 2004; Yuan and Carbaugh, 2007). Picking fruit before adequate maturity may lead to poor storability and poor fruit quality. On the other hand, some apple cultivars such as Fuji have little or no preharvest fruit abscission (PFA). The molecular mechanism responsible for this difference in PFA among apple cultivars is not clear, but extensive molecular research has revealed that certain groups of genes involved with ethylene biosynthesis, perception, and fruit softening are differentially expressed during fruit ripening and abscission (Dal Cin et al., 2006; Lashbrook et al., 1994). Apples are typical climacteric fruit characterized by a drastic increase in ethylene production and respiration at ripening (Blanpied, 1972; Yuan and Carbaugh, 2007). It has been reported that the occurrence of the respiratory climacteric and high levels of endogenous ethylene are correlated with PFA and fruit ripening (Blanpied, 1972; Yuan and Carbaugh, 2007). Application of ethephon, an ethylene-releasing compound, effectively promoted PFA and ripening in apples (Edgerton and Blanpied, 1970), whereas aminoethoxyvinylglycine (AVG), an inhibitor of ethylene biosynthesis, or 1-methylcyclopropene (1-MCP), an inhibitor of ethylene action, reduced fruit ethylene production and delayed PFA and ripening (Schupp and Greene, 2004; Yuan and Carbaugh, 2007). In addition, MdACS1-2, an allele of $M d A C S 1$, and $M d A C O 1-2$, an allele of $M d A C O 1$, genes have been implicated in differences in fruit ethylene production, fruit softening, and storage life among apple cultivars (Costa et al., 2005; Harada et al., 2000; Sunako et al., 1999). In contrast, some reports showed that apple fruit softening is not related to the $M d A C S 1$ allelotype and ethylene production (Oraguzie et al., 2004; Wakasa et al., 2006) but related to MdPG1 (Wakasa et al., 2006). It has been found that fruit abscission-related EG and PG genes are significantly different from those associated with fruit softening in tomato (Solanum lycopersicum L.) (Brummell et al., 1999; Roberts et al., 2002; Taylor et al., 1990; Taylor and Whitelaw, 2001), whereas the same EG gene (cell) is responsible for both fruit softening and mature fruit abscission in avocado (Persea americana Mill.) (Tonutti et al., 1995). However, no information is available about whether the difference in the expression of fruit softening-related PG genes such as $M d P G 1$ is also responsible for the difference in PFA among apple cultivars.

The purpose of this study was to examine the expression of genes involved in ethylene biosynthesis, ethylene perception, and cell wall degradation in the fruit abscission zone and fruit cortex of 'Golden Delicious' and 'Fuji' apples during PFA and fruit ripening and to determine the relation between the expression of these genes and the difference in PFA between these two cultivars.

\section{Materials and Methods}

Plant material. Twelve uniform 10-year-old 'Golden Delicious' apple trees and 12 uniform 9-year-old 'Fuji' apple trees on 'Mark 9' (M.9) rootstock were selected from an orchard located at Alson H. Smith, Jr. Agricultural Research and Extension Center, Winchester, VA, and blocked into three replicate groups of four 'Fuji' apple trees and four 'Golden Delicious' apple trees each in 2006. Apple trees had an average of 3-m canopy height. Twenty fruit were collected randomly from each tree at 1 - to 3-week intervals beginning on 3 Aug. 2006 ( $\approx 108$ d after full bloom) and ending on 20 Oct. Eighty fruit from each cultivar of four trees in each replicate group at each sampling time were pooled and immediately separated into fruit cortex and fruit abscission zone (FAZ). For fruit cortex collection, both skin and seeds were removed. FAZs were collected by cutting $1 \mathrm{~mm}$ at each side of the abscission fracture plane. Promptly after the separation of fruit, samples were frozen in liquid nitrogen and stored at $-80{ }^{\circ} \mathrm{C}$ for expression analysis of genes related to ethylene biosynthesis, ethylene perception, and cell wall degradation.

DETERMINATION OF FRUIT ABSCISSION, FRUIT ETHYLENE EVOLUTION, FRUIT STARCH INDEX, AND FRUIT FIRMNESS. TO determine fruit abscission rate, two limbs on each tree were tagged. Fruit on tagged limbs were counted on 3 Aug. 2006, and then fruit remaining on tagged limbs were counted weekly beginning on 3 Sept. and ending on 8 Nov. To determine fruit ethylene production, six fruit were collected from each tree at 1- to 3-week intervals beginning on 3 Aug. and ending on 6 Nov. 2006. Fruit were enclosed in a 3.8-L container and incubated for $3 \mathrm{~h}$. A 1-mL gas sample was then withdrawn from the sealed container through the rubber septum affixed to the lid, and ethylene concentration was measured with a gas chromatograph (GC) equipped with an activated alumina column and flame ionization detector (model 3700; Varian, Palo Alto, CA) (Yuan and Carbaugh, 2007). Ten fruit were also sampled from each cultivar of four trees in each replicate group to determine fruit firmness and starch index as described by Yuan and Carbaugh (2007). Briefly, fruit firmness was measured on two sides of each fruit with an Effegi penetrometer (Model FT 327; McCormick Fruit Tech, Yakima, WA) with an 11.1-mmdiameter probe. Each apple fruit was cut in half transversely and flesh starch index was evaluated by dipping half of each apple in iodine solution for $\approx 15 \mathrm{~s}$. Based on Cornell starch chart, the degree of staining was rated on a scale of 1 to 8 , in which $1=$ intense staining and $8=$ no staining (Yuan and Carbaugh, 2007).

Total RNA EXTRaction AND REAL-TIME QUANTITATIVE POLYMERASE CHAIN REACTION. Total RNA was extracted from both FAZ and fruit cortex as described by Wan and Wilkins (1994). DNA was removed from each RNA sample using a TURBO DNA-free ${ }^{T M}$ Kit (Ambion, Austin, TX). Real time polymerase chain reaction (PCR) was performed using primers that span an intron in $M d A C O$ to confirm that each RNA sample was free of genomic DNA contamination according to Dal Cin et al. (2005).

Two micrograms of total RNA was used to synthesize cDNA in a $20-\mu \mathrm{L}$ reaction volume using a High-Capacity cDNA Reverse Transcription Kit (Applied Biosystems, Foster City, CA). Real-time quantitative PCR was performed using a Power SYBR Green PCR Master Mix Kit (Applied Biosystems) on an Applied Biosystems 7500 Real-Time PCR Systems according 
to the manufacturer's instructions. Gene-specific primers were designed on non-conserved areas using Primer Expression 3.0 software (Applied Biosystems) synthesized by Integrated DNA Technologies (Coralville, IA) and the primer sequences are listed in Table 1. Real-time samples were run in triplicate and the reaction volumes were $25 \mu \mathrm{L}$. Dissociation curves were run to determine the specificity of the amplification reactions. In addition, the amplified products by real-time quantitative PCR were sequenced as described by Dal Cin et al. (2005). After validation tests, normalization to Malus Mill. actin was performed using the $\Delta \Delta \mathrm{C}_{\mathrm{T}}$ method described by Applied Biosystems (2005).

Statistical ANAlYSEs. Statistical analyses were for a randomized complete block design and included analysis of variance and Duncan's multiple range test. General linear model (GLM) procedure of SAS (Version 9.1 for Windows; SAS Institute, Cary, NC) was applied to analyze the statistical significance for gene expression by comparing the means of replicates at certain time points from different treatments $(P \leq 0.05)$.

\section{Results}

Fruit AbSCISSION, FRUIT ETHYLENE, FRUIT FIRMNESS, AND FRUIT STARCH INDEX. In 'Golden Delicious' apple trees, no fruit abscission occurred until 18 Sept. ( $\approx 153 \mathrm{~d}$ after full bloom), and fruit abscission increased rapidly thereafter (Fig. 1A). On the other hand, no fruit abscission occurred over the entire measurement period with 'Fuji' apple trees. Overall, fruit firmness decreased with time for both cultivars (Fig. 1B). However, fruit firmness decreased much more rapidly in 'Golden Delicious' apples than in 'Fuji' apples. Fruit ethylene production was undetectable by GC on 3 Aug. and 24 Aug. and still very low on 31 Aug. and 11 Sept. in both cultivars (Fig. 1C). Fruit ethylene production started to increase on 18 Sept. and increased dramatically thereafter in 'Golden Delicious' apples, whereas it increased only slightly in 'Fuji' apples. Fruit starch index increased with time for both cultivars with no significant difference between these two cultivars except for a slight difference on 28 Sept. (Fig. 1D).

EXPRESSION OF GENES ENCODING ENZYMES INVOLVED IN ETHYLENE BIOSYNTHESIS. The differential expression of genes involved in ethylene biosynthesis was analyzed before and after the onset of PFA and fruit ripening. The transcripts of MdACS1, $M d A C S 3, M d A C S 5 A, M d A C S 5 B$, and $M d A C O 1$ were detected in the fruit cortex for both cultivars (Figs. 2A, 2C, 3A, 3C, and $3 \mathrm{E})$, but no expression of $M d A C S 2$ was detected in any samples (data not shown). The transcripts of MdACS1, MdACS3, $M d A C S 5 A$, and $M d A C O 1$ in the fruit cortex were low or undetectable on 3 Aug. and 11 Sept. for both cultivars except for a rapid increase in the level of $M d A C S 3$ transcripts on 11 Sept. in 'Golden Delicious' apples. After the onset of fruit ripening, the expression levels of these four genes in the fruit cortex increased for both cultivars but at different rates. The transcript levels of $M d A C S 1, M d A C S 3, M d A C S 5 A$, and $M d A C O 1$ in the fruit cortex increased $\approx 13,000-, 63,000-, 18-$, and 4,000-fold from 3 Aug. to 10 Oct. in 'Golden Delicious' apples, respectively. However, the levels of MdACS1, $M d A C S 3, M d A C S 5 A$, and $M d A C O 1$ transcripts in the fruit cortex were only 38-, 4600-, 5-, and 1800-fold higher on 10 Oct. than on 3 Aug. in 'Fuji' apples, respectively. In contrast to the other four genes, a low level of $M d A C S 5 B$ transcript was somewhat constitutive in the fruit cortex irrespective of the cultivar.

Unlike the MdACS1 expression pattern in the fruit cortex, $M d A C S 1$ expression in the FAZ decreased from 3 Aug. to 20 Oct., although the decrease was gradual in 'Golden Delicious' apples from 3 Aug. to 28 Sept., whereas it decreased rapidly in 'Fuji' apples (Fig. 2B). In the FAZ, no significant difference was observed in $M d A C S 1$ transcript level between these two cultivars, except on 3 Aug. and 20 Oct. Also, the levels of $M d A C S 3$ transcripts were similar between the two cultivars, except on 10 and 20 Oct. (Fig. 2D). Little change was shown in the level of $M d A C S 5 B$ mRNA for either cultivar (Fig. 3D). The transcript levels of MdACS5A and MdACO1 in the FAZ of 'Fuji' apples were also low and did not substantially fluctuate from 3 Aug. to 20 Oct. (Figs. 3B and F). On the other hand, the transcript levels of $M d A C S 5 A$ and $M d A C O 1$ in the FAZ of 'Golden Delicious' apples were low on 3 Aug. and 11 Sept., just before the beginning of PFA, but increased $\approx 6$ - and 13 -fold from 11 Sept. to 10 Oct., respectively.

EXPRESSION OF GENES ENCODING ENZYMES INVOLVED IN ETHYLENE PERCEPTION AND SIGNAL TRANSDUCTION. Overall, the

Table 1. Gene-specific primers used for the expression analysis of genes related to ethylene biosynthesis, perception, signal transduction, and cell wall degradation in 'Golden Delicious' and 'Fuji' apples.

\begin{tabular}{|c|c|c|c|}
\hline Gene & Accession no. & Forward primer & Reverse primer \\
\hline$\overline{M d A c t i n}$ & CN938023 & 5' -TGACCGAATGAGCAAGGAAATTACT-3' $^{\prime}$ & 5'-TACTCAGCTTTGGCAATCCACATC-3' \\
\hline$M d A C S 1$ & L31347 & 5'-GCCTTCCGGGTTTTCGA-3' & 5'-GGCGGCCACAACCATGT-3' \\
\hline$M d A C S 3$ & U73816 & 5'-CCGGTGATGCTTTGCTTGTT-3' & $5^{\prime}$-СТCСАССТСАAАТСТСТАТСАAАCC-3' \\
\hline$M d A C S 5 B$ & AB034993 & 5'-GAATTTTGAGTGTTGGATACCTTCTTT-3' & 5'-GAACCAACATCTAAAATCCCATTGT-3' \\
\hline$M d A C O 1$ & AF030859 & 5'-CAGTCGGATGGGACCAGAA-3' & 5'-GCTTGGAATTTCAGGCCAGA-3' \\
\hline MdETR1 & AF032448 & 5'-TTGGCCTGTGAAGAGCAGT-3' & 5'-TGCAAACCATGTAGAGCCAT-3' \\
\hline MdETR2 & DQ847145 & 5'-GTTGTGACGCGGAAAATGC-3' & 5'-AATCCAGATGAAACGGCAGTTAC-3' \\
\hline MdERS1 & AY083169 & 5'-CAACTAGGGATATGCGAC-3' & 5'-CACTGGCATCCAAAGACTTC-3' \\
\hline$M d E R S 2$ & AB213028 & 5'-GCTTGTTAAGGTTGGAAGAAATCTG-3' & 5'-CGGCATCGTTGAGTGTTACATT-3' \\
\hline MdCTR1 & AY670703 & 5'-ACAAGATTTTCATGCCGAAC-3' & 5'-TATGGACAAGTTTGGAGGCT-3' \\
\hline$M d P G 1$ & L27743 & 5'-CGCACAACAAATCCATGTCATAT-3' & 5'-ACCGTGAGACAGGAAGCTTGA-3' \\
\hline$M d P G 2$ & AB210897 & 5'-CGGTTCAGCCGACAAGTTG-3' & 5'-TACGAGTGAGGAGGAGTAGATGGA-3' \\
\hline
\end{tabular}



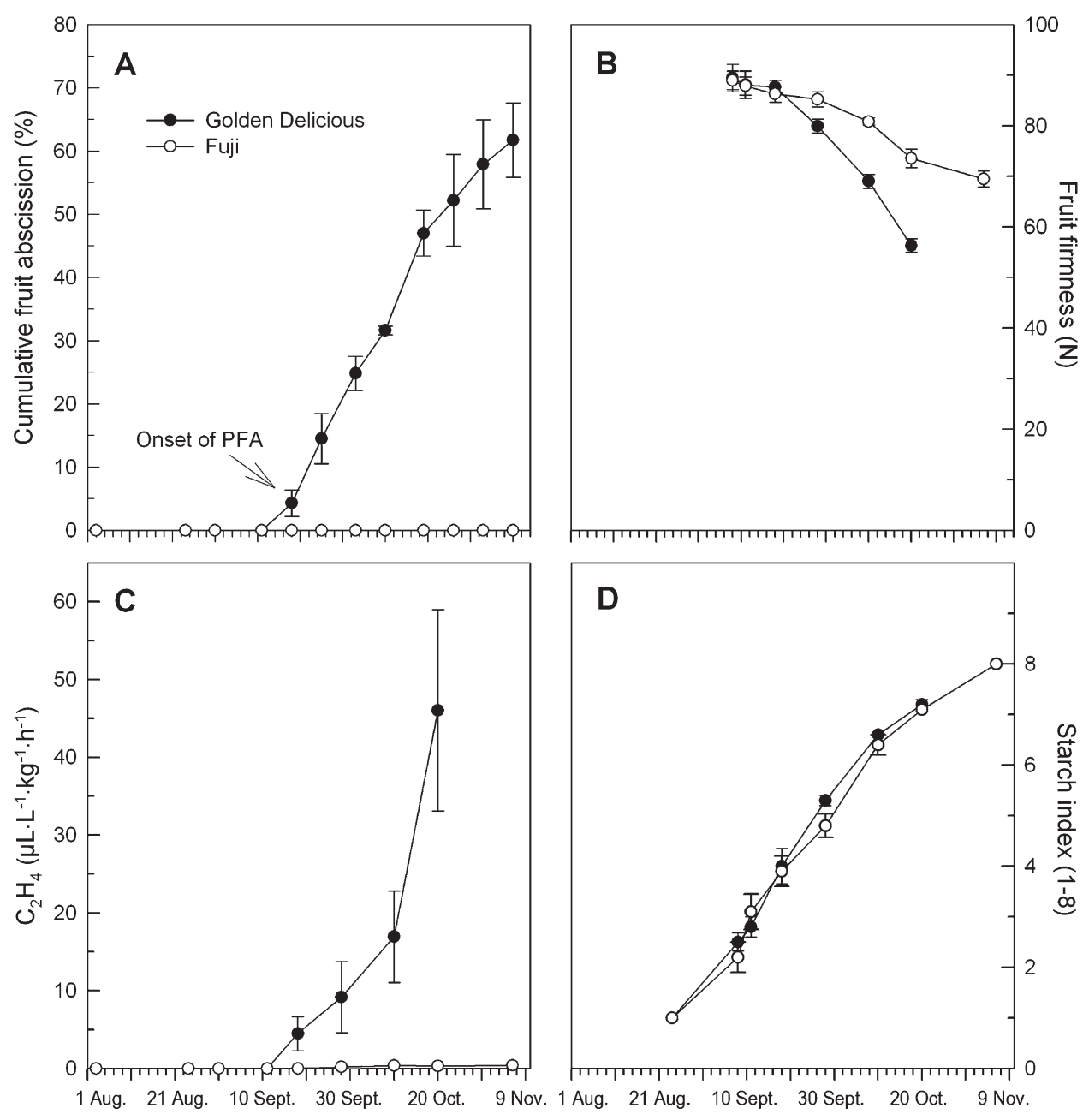

Date

Fig. 1. Fruit abscission (A), fruit firmness (B), fruit ethylene production $(\mathbf{C})$, and fruit starch index $(\mathbf{D})$ in 'Golden Delicious' and 'Fuji' apples in 2006. Data are means $\pm \mathrm{sE}[\mathrm{n}=12,30,12$, and 30 in (A), (B), (C), and (D), respectively]. The starch index (1-8) was rated based on the Cornell starch chart in which $1=$ intense staining and $8=$ no staining.

levels of MdETR1, MdETR2, MdERS1, and MdERS2 transcripts in the fruit cortex were low on 3 Aug. and 11 Sept. for both 'Golden Delicious' and 'Fuji' apples except for a significant increase in the level of MdETRI on 11 Sept. for 'Golden Delicious' apples (Figs. 4A, 4E, 5A, and 5C). The expression levels of these genes increased thereafter in the fruit cortex for both cultivars, but the increase was gradual in the fruit cortex of 'Fuji' apples, whereas it was dramatic in the fruit cortex of 'Golden Delicious' apples. However, MdETRIb gene expression was low and did not change substantially in the fruit cortex of either 'Golden Delicious' or 'Fuji' apples (Fig. 4C). The expression of MdETRIb in the fruit cortex between these two cultivars from 11 Sept. to 10 Oct. was similar. MdCTR1 expression slightly increased in the fruit cortex of 'Golden Delicious' apples at the onset of fruit ripening but not in 'Fuji' apples (Fig. 5E).

Overall, the FAZ of 'Golden Delicious' apples had higher levels of MdETR1, MdETR2, MdERS1, and MdERS2 transcripts than those of 'Fuji' apples, but there was no difference in MdETRIb expression in the FAZ between these two cultivars (Figs. 4B, 4D, 4F, 5B, and 5D). The expression levels of
MdETR2 and MdERS2 in the FAZ of 'Golden Delicious' apples increased after the onset of fruit ripening and PFA. The level of MdETRI mRNA also slightly increased in the FAZ of 'Golden Delicious' apples from 10 Oct. to 20 Oct. However, the level of MdERS1 mRNA in the FAZ of 'Golden Delicious' apples from 3 Aug. to 20 Oct. did not change, except a slight decease in the level of MdERS1 mRNA from 3 Aug. to 11 Sept. MdETR1 and MdETR2 genes were also constitutively expressed in the FAZ of 'Fuji' apples from 3 Aug. to 20 Oct. The levels of MdERS1 and MdERS2 transcripts in the FAZ of 'Fuji' apples even slightly decreased from 3 Aug. to 20 Oct.

MdCTR1 transcript level in the FAZ for both cultivars decreased slightly from 3 Aug. to 20 Oct. (Fig. 5F). 'Fuji' apples had a slightly higher MdCTRI transcript level in the FAZ than 'Golden Delicious' apples on 3 Aug. and 11 Sept., but there was no more significant difference in MdCTR1 expression in the FAZ between these two cultivars thereafter.

EXPRESSION OF GENES ENCODING ENZYMES INVOLVED IN CELL WALL DEGRADATION. $M d P G 1$ mRNA level in the fruit cortex of 'Golden Delicious' apples was very low before fruit ripening on 3 Aug. and 11 Sept., but increased $\approx 400,000$-fold from 11 Sept. to 28 Sept. and continued to increase thereafter (Fig. 6A). $M d P G 2$ transcript level in the fruit cortex of 'Golden Delicious' apples also increased on 10 Oct. after fruit ripening started, but the 250-fold increase from 3 Aug. to 20 Oct. was very small compared with a 850,000 -fold increase in $M d P G 1$ transcript level in the fruit cortex of 'Golden Delicious' apples (Fig. 6C). However, the transcript levels of $M d P G 1$ and $M d P G 2$ in the fruit cortex of 'Fuji' apples only slightly increased from 3 Aug. to 20 Oct. and were much lower than that of 'Golden Delicious' apples. By contrast, the level of $M d E G 1$ mRNA did not significantly change in the fruit cortex of 'Golden Delicious' apples over the time period examined, whereas they increased $\approx 6$-fold in the fruit cortex of 'Fuji' apples from 3 Aug. to 28 Sept. and decreased thereafter (Fig. $6 \mathrm{E})$. Overall, the fruit cortex of 'Fuji' apples had a higher level of MdEG1 mRNA than that of 'Golden Delicious' apples.

Unlike $M d P G 1$ expression in the fruit cortex, $M d P G 1$ expression pattern was erratic in the FAZ for both cultivars (Fig. 6B). Conversely, MdPG2 transcript level in the FAZ increased 8400-fold in 'Golden Delicious' apples from 11 Sept. to 20 Oct., whereas the level of $M d P G 2$ transcripts in the FAZ only increased $\approx 3$-fold in 'Fuji' apples from 3 Aug. to 10 Oct. and continued to increase slightly from 10 Oct. to 20 Oct. (Fig. 


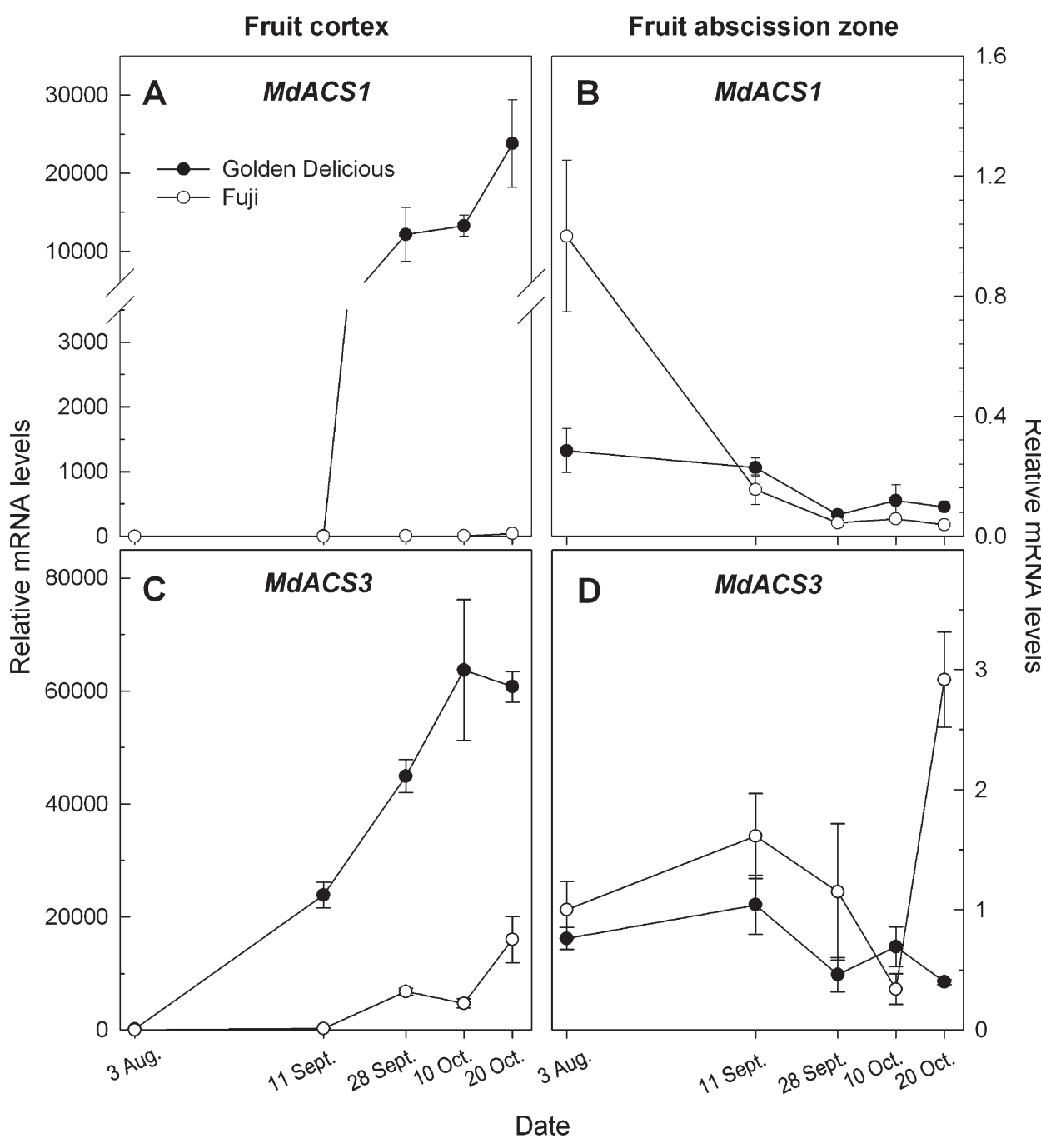

Fig. 2. Real-time quantitative polymerase chain reaction analysis of the expression of $M d A C S 1$ and $M d A C S 3$ in the fruit cortex (A and C) and fruit abscission zone (FAZ) (B and D) of 'Golden Delicious' and 'Fuji' apples. The mRNA levels of MdACS1 and MdACS3 were normalized using Malus actin. Data are means $\pm \mathrm{SE}(\mathrm{n}=3)$. The values of MdACS1 and MdACS3 in the fruit cortex and FAZ of 'Fuji' apples on 11 Sept. and 3 Aug. were arbitrarily set to 1 , respectively.

6D). The level of $M d E G 1$ mRNA also increased $\approx 10$-fold in the FAZ of 'Golden Delicious' apples from 11 Sept. to 28 Sept. and remained high thereafter (Fig. 6F). However, the level of MdEG1 mRNA in the FAZ of 'Fuji' apples was low and did not significantly change over the time period examined.

\section{Discussion}

Apple fruit ethylene production, abscission, And RIPENING. It has been reported that a burst increase in fruit ethylene production is associated with fruit ripening and fruit abscission in some climacteric fruit such as cantaloupe melon (Cucumis melo L.) (Ayub et al., 1996; Guis et al., 1997), avocado (Tonutti et al., 1995), and apple (Blanpied, 1972; Yuan and Carbaugh, 2007). In this study, 'Golden Delicious' apples showed a marked increase in fruit ethylene production and fruit abscission and a rapid decrease in fruit firmness during fruit ripening, whereas 'Fuji' apples had a very low ethylene production, a gradual decrease in fruit firmness, and low or no PFA. These comparative results clearly proved that fruit softening and abscission response were dependent of fruit ethylene production. This was also consistent with previous reports that when the ripening-related increase in ethylene production was inhibited by antisense ACC oxidase in cantaloupe melon (Ayub et al., 1996; Guis et al., 1997) or application of AVG or 1-MCP in apple (Li and Yuan, 2008; Schupp and Greene, 2004; Yuan and Carbaugh, 2007), fruit softening was delayed and fruit abscission was reduced. Although the relationship between fruit ethylene production and fruit abscission is obvious when certain apple cultivars are considered, a recent study, which looked at a broader range of apple genetic materials, has revealed other apple varieties that showed fruit abscission before substantial ethylene production as well as those that did not show fruit abscission although with high levels of fruit ethylene. Therefore, the authors suggested important roles for the mechanism independent of fruit ethylene production in fruit abscission (Sun et al., 2009). Taken together, further research is necessary to better understand the relationships among ethylene, abscission, and ripening in apples.

EXPRESSION OF 1-AMINOCYCLOPROPANE-1-CARBOXYLATE SYNTHASE AND 1-AMINOCYCLOPROPANE-1CARBOXYLATE OXIDASE GENES IN APPLE FRUIT AND FRUIT ABSCISSION ZONE DURING FRUIT ABSCISSION AND RIPENING. The regulation of ethylene biosynthesis by various stresses and developmental cues is mainly through differential expression of ACC synthase and ACC oxidase genes (Kende, 1993; Wang et al., 2002; Yuan et al., 2005). Our data clearly showed that expression of $M d A C S 3, M d A C S 5 A$, and $M d A C O 1$ increased in the fruit cortex for both 'Golden Delicious' apples with climacteric ethylene production and 'Fuji' apples without climacteric ethylene production during fruit ripening. However, only the MdACS1 gene was highly expressed in the fruit cortex in 'Golden Delicious' apples during ripening, but not in 'Fuji' apples. These results suggested that an increased expression of MdACS1 in the fruit cortex may be responsible for the climacteric ethylene production in apples during ripening, whereas expression of $M d A C S 3$ and $M d A C S 5 A$ was developmentally dependent and not associated with the climacteric ethylene production in apples during ripening. These findings were in agreement with previous reports that fruit ethylene production was reduced and fruit softening was delayed in MdACS1 gene-silenced mature apple fruit (Dandekar et al., 2004). Similarly, AVG, an inhibitor of ethylene biosynthesis, 


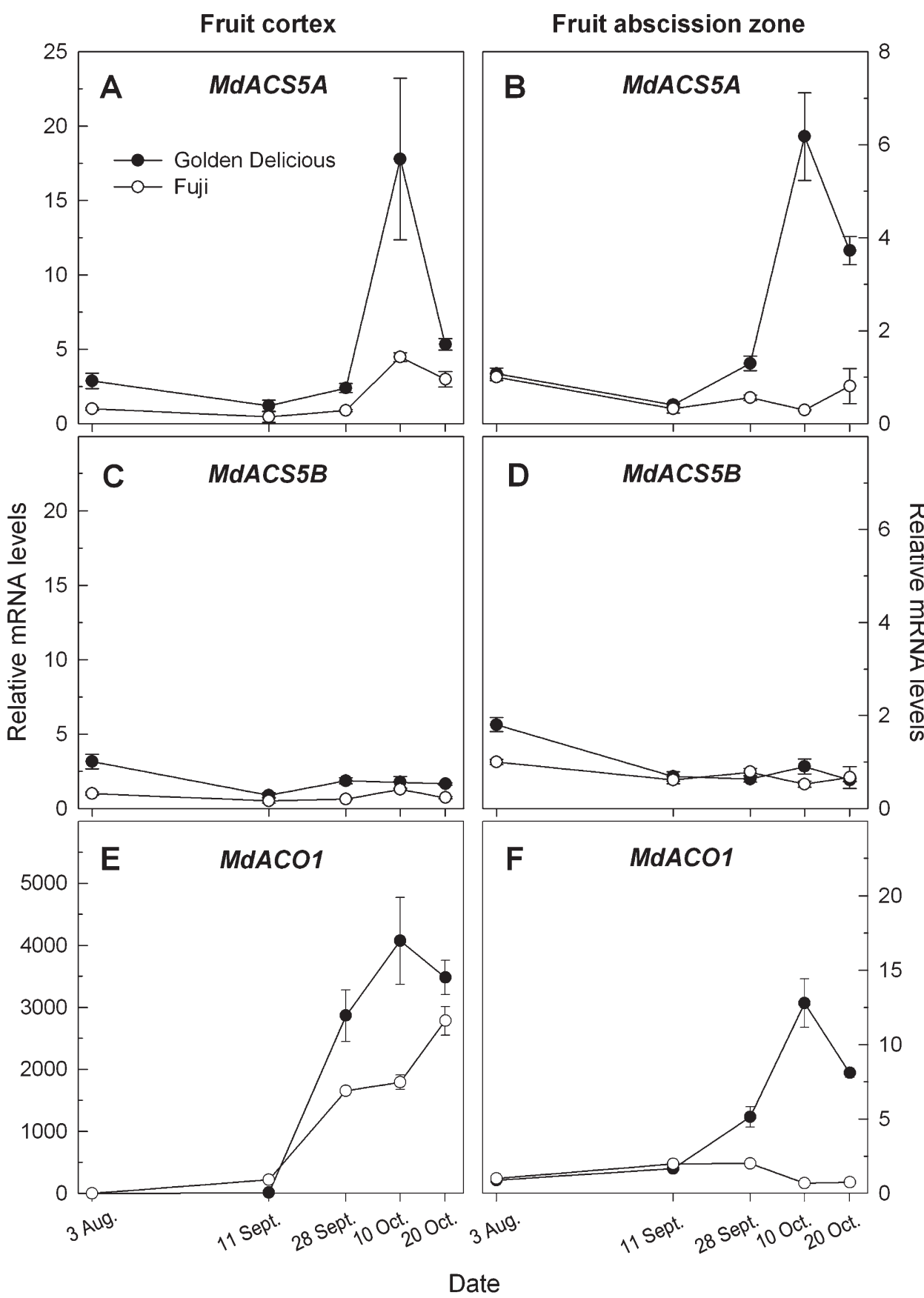

Fig. 3. Real-time quantitative polymerase chain reaction analysis of the expression of MdACS5A, MdACS5B, and $M d A C O 1$ in the fruit cortex (A, C, and $\mathbf{E}$ ) and fruit abscission zone (FAZ) (B, D, and $\mathbf{F}$ ) of 'Golden Delicious' and 'Fuji' apples. The mRNA levels of MdACS5A, MdACS5B, and MdACO1 were normalized using Malus actin. Data are means $\pm \mathrm{SE}(\mathrm{n}=3)$. The values of MdACS5A, MdACS5B, and MdACO1 in the fruit cortex and FAZ of 'Fuji' apples on 3 Aug. were arbitrarily set to 1, respectively.

and 1-MCP, an inhibitor of ethylene action, inhibited expression of MdACS1 and MdACO1 in the fruit cortex, climacteric ethylene production and fruit softening in 'Red Delicious' apples, but it had no effect on the levels of MdACS3 and MdACS5A mRNA in the fruit cortex (Li and Yuan, 2008). The lack of a tight association between ethylene evolution and the levels of MdACS3, MdACS5A, and MdACO1 transcripts in 'Fuji' apple fruit may be the result of to a post-transcriptional regulation negatively influencing translation, protein activity, and turnover (Dal Cin et al., 2005; Wiersma et al., 2007). A similar association between ethylene evolution and the level of $M d A C O 1$ mRNA was also observed in young apple fruit (Dal Cin et al., 2005) and MdACS1 gene-silenced mature apple fruit (Dandekar et al., 2004). On the other hand, MdACS5B may be related to basal ethylene synthesis in apple fruit, which was in accordance with previous report that $M d A C S 5 B$ was the only ACS gene detected in young apple fruit (Dal Cin et al., 2005).

It was unlikely that $M d A C S 1$ and $M d A C S 3$ were involved in PFA in apples because $M d A C S 1$ expression decreased in the FAZ in both 'Golden Delicious' and 'Fuji' apples during PFA, and no significant difference in the level of MdACS3 transcripts in the FAZ was observed between these two cultivars. This was consistent with previous reports that $1-\mathrm{MCP}$ and AVG inhibited ethylene production and fruit abscission in 'Red Delicious' apples, but they had no effects on the expression of $M d A C S 1$ and $M d A C S 3$ in the FAZ (Li and Yuan, 2008). $M d A C S 5 B$ may not be related to PFA either, because there was no difference in the expression level of $M d A C S 5 B$ in the FAZ between 'Golden Delicious' and 'Fuji' apples. In contrast, the expression of MdACS5A and MdACOI markedly increased in the FAZ during PFA in 'Golden Delicious' apples but not in 'Fuji' apples, which had no PFA. Preharvest 1-MCP treatment also inhibited the expression of $M d A C S 5 A$ and $M d A C O 1$ in the FAZ and reduced PFA in 'Red Delicious' apples (Li and Yuan, 2008). These results suggested that $M d A C S 5 A$ and $M d A C O 1$ were associated with PFA in apples.

The suggestion that MdACS1 is related to climacteric fruit ethylene production and fruit ripening, whereas MdACS5A is associated with PFA, was supported by our previous finding that dipping 'Granny Smith' apple fruit into a solution of ACC or ethephon at $600 \mathrm{mg} \cdot \mathrm{L}^{-1}$, avoiding any contact with $\mathrm{FAZ}$ after fruit started ripening, markedly stimulated fruit ethylene production and fruit softening but it did not induce PFA (data not shown). Similarly, Blanpied (1972) reported that the ethylene produced in ripening fruit unlikely diffused to FAZ through the fruit pedicel and caused PFA because the ethylene level in the fruit pedicel did not increase when the fruit of 'Golden Delicious' 


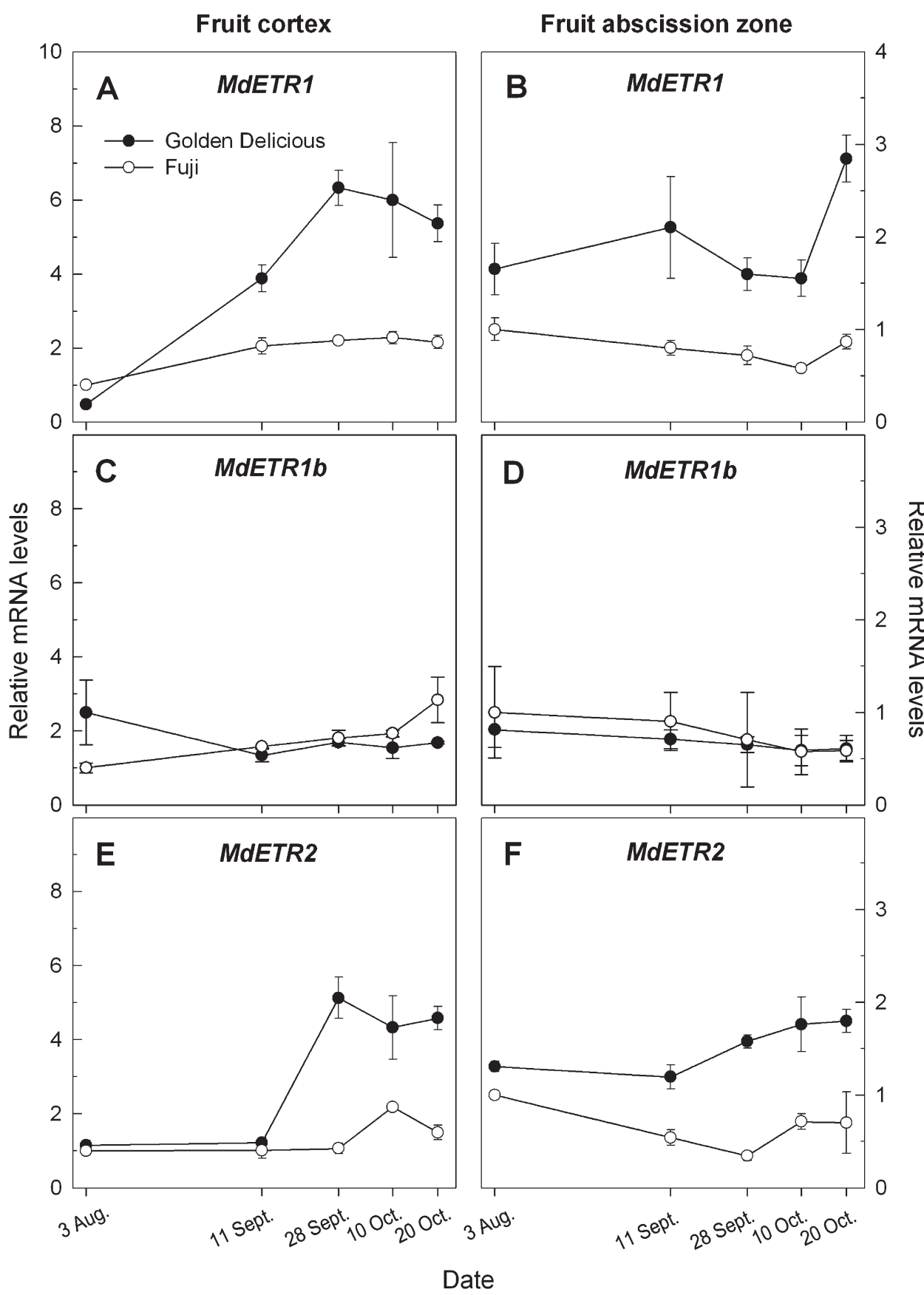

Fig. 4. Real-time quantitative polymerase chain reaction analysis of the expression of MdETR1, MdETR $1 b$, and MdETR2 in the fruit cortex (A, C, and E) and fruit abscission zone (FAZ) (B, D, and F) of 'Golden Delicious' and 'Fuji' apples. The mRNA levels of MdETR1, MdETR1b, and MdETR2 were normalized using Malus actin. Data are means \pm SE $(\mathrm{n}=3)$. The values of MdETR1, MdETR1b, and MdETR2 in the fruit cortex and FAZ of 'Fuji' apples on 3 Aug. were arbitrarily set to 1, respectively.

apple started to ripen and fruit ethylene began to increase, yet fruit abscission was well underway.

EXPRESSION OF ETR AND ERS GENES IN APPLE FRUIT AND FRUIT ABSCISSION ZONE DURING FRUIT ABSCISSION AND RIPENING. Overall, the FAZ of 'Golden Delicious' apples had higher levels of MdETR1, MdETR2, MdERS1, and MdERS2 transcripts than those of 'Fuji' apples. In addition, the levels of MdETR2 and MdERS2 mRNA in the FAZ of 'Golden Delicious' apples increased during PFA and ripening, whereas there was no significant change in the levels of MdETR1, MdETR1b, and MdETR2 transcripts or a decrease in the levels of MdERS1 and $M d E R S 2$ transcripts in the FAZ of 'Fuji' apples, which had no PFA. These results suggested that at least $M d E T R 2$ and MdERS2 were related to PFA in these two cultivars. This suggestion was supported by the results that $1-\mathrm{MCP}$ inhibited the expression of $M d E T R 2$ and $M d E R S 2$ genes in the FAZ and reduced PFA in 'Red Delicious' apples (Li and Yuan, 2008). A similar association between abscission and increased expression of ethylene receptor genes in abscission zones has been reported in flowers of tomato (Lashbrook et al., 1998; Payton et al., 1996; Whitelaw et al., 2002), leaves of tomato (Payton et al., 1996; Whitelaw et al., 2002), and young fruit of peach (Prunus persica L.) (Rasori et al., 2002) and apple (Dal Cin et al., 2005). Furthermore, reduced LeETR1 transcript level by antisense LeETR1 delayed the abscission of flowers and leaves in tomato (Whitelaw et al., 2002). However, the observed association seems controversial to the model that ethylene receptors negatively regulate ethylene responses and there is an inverse relationship between receptor levels and ethylene sensitivity of a tissue (Hua and Meyerowitz, 1998; Klee, 2004; Tieman et al., 2000). Alternatively, the increase in the levels of overall receptor mRNA during fruit abscission may be a natural response to increased ethylene biosynthesis (Dal Cin et al., 2005; Kevany et al., 2007; Klee, 2004). Further work will be necessary to determine the relationship between the levels of ethylene receptor proteins in abscission zones and fruit abscission.

Our results also demonstrated that the levels of MdETR1, MdETR2, $M d E R S 1$, and MdERS2 mRNA increased in the fruit cortex during ripening in 'Golden Delicious' and 'Fuji' apples. Similarly, a marked increase in the levels of overall receptor mRNA during fruit ripening has been observed in many climacteric fruit such as tomato (Kevany et al., 2007; Lashbrook et al., 1998; Tieman et al., 2000), muskmelon (C. melo) (Sato-Nara et al., 1999), pear (Pyrus communis L.) (El-Sharkawy et al., 2003), and apple (Dal Cin et al., 2006). The increase in the levels of overall receptor mRNA during fruit ripening has been suggested as a natural response to increased 
Fruit cortex
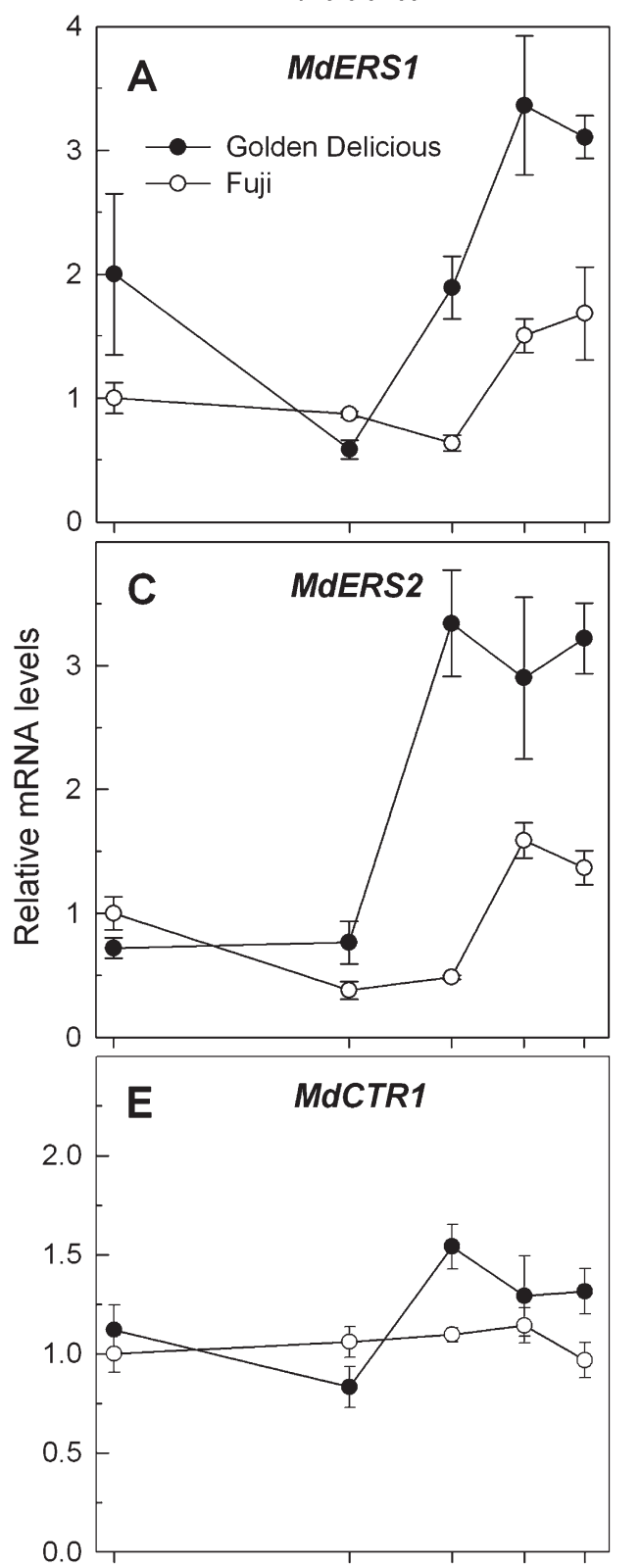

$$
3 \text { Aug. }
$$

Fruit abscission zone
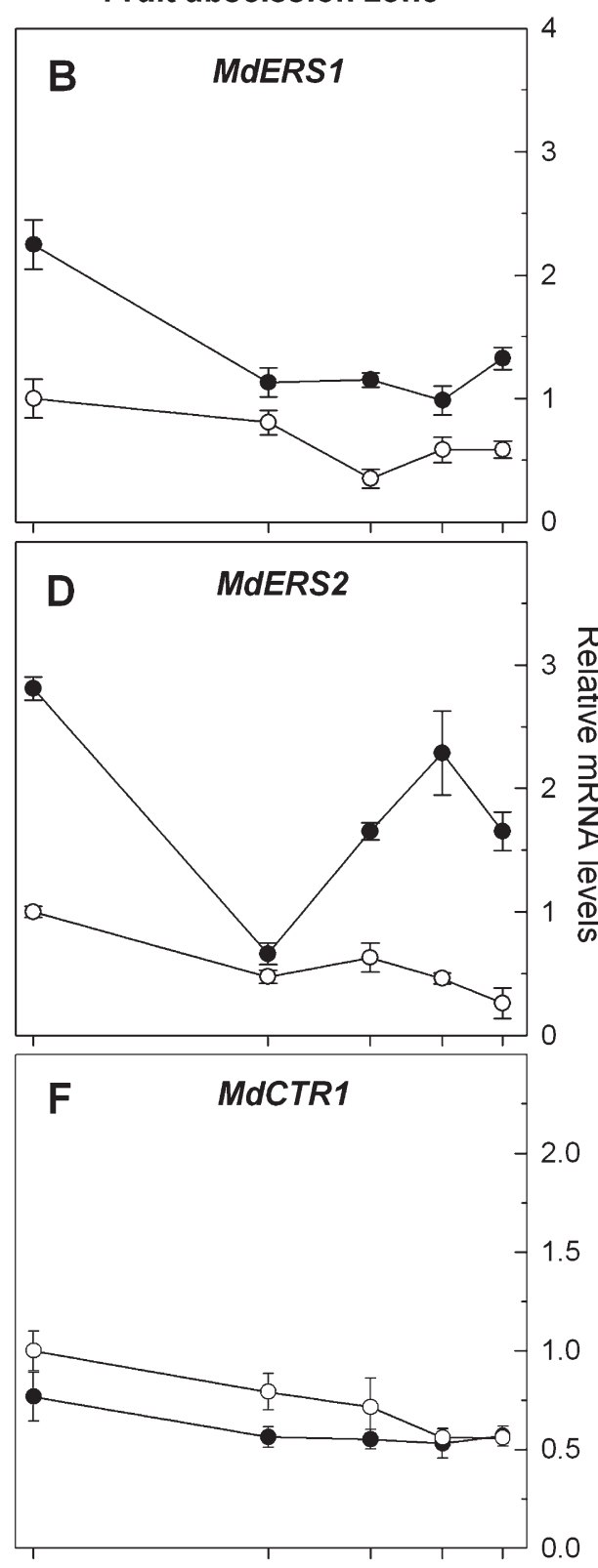

3 Aug.

Date

Fig. 5. Real-time quantitative polymerase chain reaction analysis of the expression of MdERS1, MdERS2, and MdCTR1 in the fruit cortex (A, C, and $\mathbf{E})$ and fruit abscission zone (FAZ) (B, D, and $\mathbf{F})$ of 'Golden Delicious' and 'Fuji' apples. The mRNA levels of MdERS1, MdERS2, and MdCTR1 were normalized using Malus actin. Data are means $\pm \operatorname{SE}(\mathrm{n}=3)$. The values of MdERS1, MdERS2, and MdCTRI in the fruit cortex and FAZ of 'Fuji' apples on 3 Aug. were arbitrarily set to 1, respectively.

ethylene biosynthesis and a mechanism to temper the ethylene response by decreasing ethylene sensitivity through increasing receptor abundance (Dal Cin et al., 2006; Kevany et al., 2007; Klee, 2004).

EXPRESSION OF POLYGALACTURONASE AND $\boldsymbol{\beta}$-1,4-GLUCANASE GENES IN APPLE FRUIT AND FRUIT ABSCISSION ZONE DURING FRUIT ABSCISSION AND RIPENING. Many reports have shown that an increase in PG activity is associated with fruit softening (Alexander and Grierson, 2002; Roberts et al., 2002; Wakasa et al., 2006) and abscission of leaves, flower, and fruit (Bonghi et al., 2000; Hong et al., 2000; Taylor et al., 1990). However, PG protein and the genes coding for this protein in the abscission zones of tomato leaves and flowers are significantly different from those related to fruit softening in tomato (Kalaitzis et al., 1997; Taylor et al., 1990). In our study, the expression pattern of $M d P G 1$ was erratic in the FAZ for both cultivars, suggesting that $M d P G 1$ was not related to apple fruit abscission. A rapid increase in the level of MdPG1 mRNA was observed during fruit ripening in 'Golden Delicious' apple fruit, which showed a rapid decrease in flesh firmness. Conversely, there was only a slight increase in MdPG1 expression in 'Fuji' apple fruit, which softened gradually. This was consistent with previous reports that MdPG1 is involved in apple fruit softening during ripening ( $\mathrm{Li}$ and Yuan, 2008; Wakasa et al., 2006). In contrast, a marked increase in the expression of $M d P G 2$ in the FAZ was associated with increased fruit abscission in 'Golden Delicious' apples, whereas there was only a slight increase in the level of $M d P G 2$ transcripts in the FAZ of 'Fuji' apples, which showed no PFA. Preharvest 1-MCP treatment also inhibited $M d P G 2$ expression in the FAZ and reduced fruit abscission in 'Red Delicious' apples (Li and Yuan, 2008). These results indicated that $M d P G 2$ could be responsible for fruit abscission in apples. It was unlikely that $M d P G 2$ plays a major role in apple fruit softening, because compared with a 850,000-fold increase in $M d P G 1$ transcripts, there was only a slight increase in the expression of MdPG2 in 'Golden Delicious' apple fruit during fruit ripening. In addition, the increase in $M d P G 2$ expression in fruit did not occur until 10 Oct. when fruit firmness already decreased. Taken together, the results indicated that $M d P G 1$ was related to fruit softening, whereas $M d P G 2$ was correlated with fruit abscission in apples. This was in agreement with previous reports that 1naphthaleneacetic acid increased fruit softening and decreased fruit abscission by increasing the expression of $M d P G 1$ in fruit and decreasing the expression of $M d P G 2$ in the FAZ in apple ( $\mathrm{Li}$ and Yuan, 2008).

The results obtained in this study were consistent with previous reports that cellulase is involved in fruit abscission 


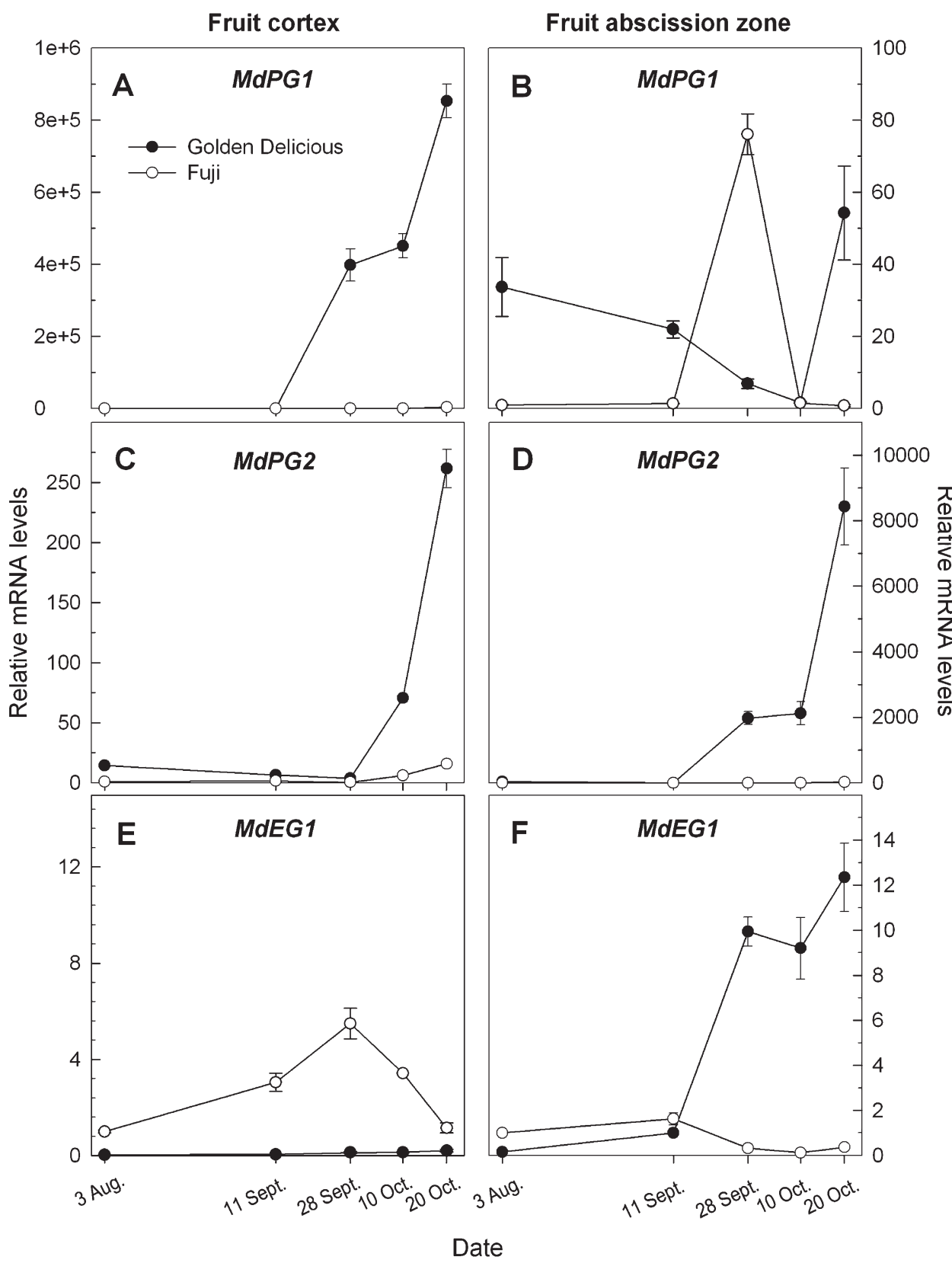

Fig. 6. Real-time quantitative polymerase chain reaction analysis of the expression of $M d P G 1, M d P G 2$, and $M d E G 1$ in the fruit cortex $(\mathbf{A}, \mathbf{C}$, and $\mathbf{E})$ and fruit abscission zone (FAZ) (B, D, and F) of 'Golden Delicious' and 'Fuji' apples. The mRNA levels of $M d P G 1, M d P G 2$, and MdEG1 were normalized using Malus actin. Data are means \pm SE $(\mathrm{n}=3)$. The values of $M d P G 1, M d P G 2$, and MdEG1 in the fruit cortex and FAZ of 'Fuji' apples on 3 Aug. were arbitrarily set to 1 , respectively.

(Bonghi et al., 2000; Tonutti et al., 1995). Apple fruit abscission induced by wounding or application of ethephon is correlated with increased cellulase activity in the FAZ (Ward et al., 1999). In our study, a sharp increase in the level of MdEG1 mRNA in the FAZ was associated with increased fruit abscission in 'Golden Delicious' apples, whereas a low level of MdEG1 mRNA was found in the FAZ of 'Fuji' apples, which had no fruit abscission. This result suggested that $M d E G 1$ was involved in fruit abscission in apples, which was supported by the fact that 1-MCP inhibited both MdEG1 expression in the FAZ and fruit abscission in 'Red Delicious' apples (Li and Yuan, 2008). Conversely, it seems that MdEG1 was not involved in fruit softening in apples because 'Golden Delicious' apple fruit showed basal $M d E G 1$ expression and a lower level of $M d E G 1$ mRNA than 'Fuji' apple fruit. $M d E G 1$ expression was unaffected by 1-MCP in 'Red Delicious' apple fruit also ( $\mathrm{Li}$ and Yuan, 2008). Similarly, using transgenic tomatoes with antisense cell or cel2 genes, it has been found that different cellulase genes are responsible for fruit ripening and fruit abscission or flower abscission (Brummell et al., 1999; Lashbrook et al., 1998). This was different from avocado in which the same cellullase gene (cell) is responsible for both fruit softening and mature fruit abscission (Tonutti et al., 1995).

In summary, our results suggested that ethylene biosynthesis, ethylene perception, and cell wall degradation were involved in PFA and fruit softening during fruit ripening in 'Golden Delicious' and 'Fuji' apples. $M d A C S 5 A, M d A C O 1$, MdETR2, MdERS2, MdPG2, and $M d E G 1$ in the FAZ may be the critical genes responsible for the difference in fruit abscission between these two cultivars, whereas MdACS1, MdETR2, MdERS1, $M d E R S 2$, and $M d P G 1$ likely account for the difference in fruit softening between these two cultivars.

\section{Literature Cited}

Addicott, F.T. 1982. Abscission. University of California Press, London, UK.

Alexander, L. and D. Grierson. 2002. Ethylene biosynthesis and action in tomato: A model for climacteric fruit ripening. J. Expt. Bot. 53:20392055.

Applied Biosystems. 2005. Guide to performing relative quantitation of gene expression using real-time quantitative PCR. Applied Biosystems, Foster City, CA.

Ayub, R., M. Guis, M.B. Amor, L. Gillot, J.P. Roustan, A. Latche, M. Bouzayen, and J.C. Pech. 1996. Expression of ACC oxidase antisense gene inhibits ripening of cantaloupe melon fruits. Nat. Biotechnol. 14:862-866.

Blanpied, G.D. 1972. A study of ethylene in apple, red raspberry, and cherry. Plant Physiol. 49:627-630.

Bleecker, A.B. and H. Kende. 2000. Ethylene: A gaseous signal molecule in plants. Annu. Rev. Cell Dev. Biol. 16:1-40.

Bleecker, A.B. and S.E. Patterson. 1997. Last exit: Senescence, abscission, and meristem arrest in Arabidopsis. Plant Cell 9:11691179 . 
Bonghi, C., P. Tonutti, and A. Ramina. 2000. Biochemical and molecular aspects of fruitlet abscission. Plant Growth Regulat. 31:35-42.

Brown, K.M. 1997. Ethylene and abscission. Physiol. Plant. 100:567576.

Brummell, D.A., B.D. Hall, and A.B. Bennett. 1999. Antisense suppression of tomato endo-1,4- $\beta$-glucanase Cel2 mRNA accumulation increases the force required to break FAZ but does not affect fruit softening. Plant Mol. Biol. 40:615-622.

Costa, F., S. Stella, W.E. Van de Weg, W. Guerra, M. Cecchinel, J. Dallavia, B. Koller, and S. Sansavini. 2005. Role of the genes $M d$ $A C O 1$ and $M d-A C S 1$ in ethylene production and shelf life of apple (Malus domestica Borkh). Euphytica 141:181-190.

Dal Cin, V., M. Danesin, A. Boschetti, A. Dorigoni, and A. Ramina. 2005. Ethylene biosynthesis and perception in apple fruitlet abscission (Malus domestica L. Borkh). J. Expt. Bot. 56:29953005.

Dal Cin, V., F.M. Rizzini, A. Botton, and P. Tonutti. 2006. The ethylene biosynthetic and signal transduction pathways are differently affected by 1-MCP in apple and peach fruit. Postharvest Biol. Technol. 42:125-133.

Dandekar, A.M., G. Teo, B.G. Defilippi, S.L. Uratsu, A.J. Passey, A.A. Kader, J.R. Stow, R.J. Colgan, and D.J. James. 2004. Effect of downregulation of ethylene biosynthesis on fruit flavor complex in apple fruit. Transgenic Res. 13:373-384.

Edgerton, L.J. and G.D. Blanpied. 1970. Interaction of succinic acid 2, 2-dimethyl hydrazide, 2-chloroethylphosphonic acid and auxins on maturity, quality and abscission of apples. J. Amer. Soc. Hort. Sci. 95:64-66.

El-Sharkawy, I., B. Jones, Z. Li, J. Lelievre, J.C. Pech, and A. Latche. 2003. Isolation and characterization of four ethylene perception elements and their expression during ripening in pears with/without cold requirement. J. Expt. Bot. 54:615-625.

Guis, M., R. Botondi, M.B. Amor, R. Ayub, M. Bouzayen, J.C. Pech, and A. Latche. 1997. Ripening-associated biochemical traits of cantaloupe Charentais melons expressing an antisense ACC oxidase transgene. J. Amer. Soc. Hort. Sci. 122:748-751.

Harada, T., T. Sunako, Y. Wakasa, J. Soejima, T. Satoh, and M. Niizeki. 2000. An allele of the 1-aminocyclopropane-1-carboxylate synthase gene (Md-ACS1) accounts for the low level of ethylene production in climacteric fruits of some apple cultivars. Theor. Appl. Genet. 101:742-746.

Hong, S.B., R. Sexton, and M.L. Tucker. 2000. Analysis of gene promoters for two tomato polygalacturonases expressed in abscission zones and the stigma. Plant Physiol. 123:869-881.

Hua, J. and E.M. Meyerowitz. 1998. Ethylene responses are negatively regulated by a receptor gene family in Arabidopsis thaliana. Cell 94:261-271.

Kalaitzis, P., T. Solomos, and M.L. Tucker. 1997. Three different polygalacturonases are expressed in tomato leaf and flower abscission, each with a different temporal expression pattern. Plant Physiol. 113:1303-1308.

Kende, H. 1993. Ethylene biosynthesis. Annu. Rev. Plant Physiol. Plant Mol. Biol. 44:283-307.

Kevany, B.M., D.M. Tieman, M.G. Taylor, V. Dal Cin, and H.J. Klee. 2007. Ethylene receptor degradation controls the timing of ripening in tomato fruit. Plant J. 51:458-467.

Klee, H.J. 2004. Ethylene signal transduction. Moving beyond Arabidopsis. Plant Physiol. 135:660-667.

Lashbrook, C.C., C. Gonzalez-Bosch, and A.B. Bennett. 1994. Two divergent endo- $\beta$-1,4-glucanase genes exhibit overlapping expression in ripening fruit and abscising flowers. Plant Cell 6:14851493.

Lashbrook, C.C., D.M. Tieman, and H.J. Klee. 1998. Differential regulation of the tomato ETR gene family throughout plant development. Plant J. 15:243-252.

Li, J. and R. Yuan. 2008. NAA and ethylene regulate expression of genes related to ethylene biosynthesis, perception and cell wall degradation during fruit abscission and ripening in 'Delicious' apples. J. Plant Growth Regul. 27:283-295.

Oraguzie, N.C., H. Iwanami, J. Soejima, T. Harada, and A. Hall. 2004. Inheritance of the $M d-A C S 1$ gene and its relationship to fruit softening in apple (Malus $\times$ domestica Borkh). Theor. Appl. Genet. 108:1526-1533.

Osborne, D.J. 1989. Abscission. Crit. Rev. Plant Sci. 8:103-129.

Patterson, S.E. and A.B. Bleecker. 2004. Ethylene-dependent and -independent process associated with floral organ abscission in Arabidopsis. Plant Physiol. 134:194-203.

Payton, S., R.G. Fray, S. Brown, and D. Grierson. 1996. Ethylene receptor expression is regulated during fruit ripening, flower senescence and abscission. Plant Mol. Biol. 31:1227-1231.

Rasori, A., B. Ruperti, C. Bonghi, P. Tonutti, and A. Ramina. 2002. Characterization of two putative ethylene receptor genes expressed during peach fruit development and abscission. J. Expt. Bot. 53: 2333-2339.

Roberts, J.A., K.A. Elliott, and Z.H. Gonzalez-Carranza. 2002. Abscission, dehiscence, and other cell separation process. Annu. Rev. Plant Biol. 53:131-158.

Sato-Nara, K., K. Yuhashi, K. Higashi, K. Hosoya, M. Kubota, and H. Ezura. 1999. Stage- and tissue-specific expression of ethylene receptor homologue genes during fruit development in muskmelon. Plant Physiol. 119:321-329.

Schupp, J.R. and D.W. Greene. 2004. Effect of aminoethoxyvinylglycine (AVG) on preharvest drop, fruit quality, and maturation of 'McIntosh' apples. I. Concentration and timing of dilute applications of AVG. HortScience 39:1030-1035.

Sun, L.X., M.J. Bukovac, P.L. Forsline, and S. van Nocker. 2009. Natural variation in fruit abscission-related traits in apple (Malus). Euphytica 165:55-67.

Sunako, T., W. Sakuraba, M. Senda, S. Akada, R. Ishikawa, M. Niizeki, and T. Harada. 1999. An allele of the ripening-specific 1-aminocyclopropane-1-carboxylic acid synthase gene (ACS1) in apple fruit with a long storage life. Plant Physiol. 119:12971303.

Taylor, J.E., G.A. Tucker, Y. Lasslett, C.J.S. Smith, C.M. Arnold, C.F. Watson, W. Schuch, D. Grierson, and J.A. Roberts. 1990. Polygalacturonase expression during leaf abscission of normal and transgenic tomato plants. Planta 183:133-138.

Taylor, J.E. and C.A. Whitelaw. 2001. Signals in abscission. New Phytol. 151:323-339.

Tieman, D.V., M.G. Taylor, J.A. Ciardi, and H.J. Klee. 2000. The tomato ethylene receptors NR and LeETR4 are negative regulators of ethylene response and exhibit functional compensation within a multigene family. Proc. Natl. Acad. Sci. USA 97:56635668.

Tonutti, P., L.G. Cass, and R.E. Christoffersen. 1995. The expression of cellulase gene family members during induced avocado fruit abscission and ripening. Plant Cell Environ. 18:709-713.

Tucker, M.L., R. Sexton, E.D. Campillo, and L.N. Lewis. 1988. Bean abscission cellulase. Plant Physiol. 88:1257-1262.

Wakasa, Y., H. Kudo, R. Ishikawa, S. Akada, M. Senda, M. Niizeki, and T. Harada. 2006. Low expression of an endopolygalacturonase gene in apple fruit with long-term storage potential. Postharvest Biol. Technol. 39:193-198.

Wan, C.Y. and T.A. Wilkins. 1994. A modified hot borate method significantly enhances the yield of high-quality RNA from cotton (Gossypium hirsutum L.). Anal. Biochem. 223:7-12.

Wang, K.L.C., H. Li, and J.R. Ecker. 2002. Ethylene biosynthesis and signaling networks. Plant Cell 14:S131-S151.

Ward, D.L., E.P. Beers, R.E. Byers, and R.P. Marini. 1999. Cutting apple fruit induces cellulase activity in the abscission zone. HortScience 34:601-603.

Whitelaw, C.A., N.N. Lyssenko, L. Chen, D. Zhou, A.K. Mattoo, and M.L. Tucker. 2002. Delayed abscission and shorter internodes correlate with a reduction in the ethylene receptor LeETRI transcript in transgenic tomato. Plant Physiol. 128:978-987. 
Wiersma, P.A., H. Zhang, C. Lu, A. Quail, and P.M.A. Toivonen. 2007. Survey of the expression of genes for ethylene synthesis and perception during maturation and ripening of 'Sunrise' and 'Golden Delicious' apple fruit. Postharvest Biol. Technol. 44: 204-211.

Yang, S.F. and N.E. Hoffman. 1984. Ethylene biosynthesis and its regulation in higher plants. Annu. Rev. Plant Physiol. 35:155189.
Yuan, R. and D.H. Carbaugh. 2007. Effects of NAA, AVG, and 1-MCP on ethylene biosynthesis, preharvest fruit drop, fruit maturity, and quality of 'Golden Supreme' and 'Golden Delicious' apples. HortScience 42:101-105.

Yuan, R., Z. Wu, I.A. Kostenyuk, and J.K. Burns. 2005. G-proteincoupled $\alpha_{2 \mathrm{~A}}$-adrenoreceptor agonists differentially alter citrus leaf and fruit abscission by affecting expression of ACC synthase and ACC oxidase. J. Expt. Bot. 56:1867-1875. 